ARCHIVO ESPAÑOL DE ARTE, LXXXV, 340

OCTUBRE-DICIEMBRE 2012, pp. 351-387

ISSN: 0004-0428

\title{
VARIA
}

\section{TRES PLACAS DE YESERÍAS MUDÉJARES EN MUSEOS EUROPEOS}

\author{
M. á Ángeles JoRdANo BARBUdo
}

\begin{abstract}
Estas placas inéditas procedentes de Toledo se encuentran en el Victoria \& Albert Museum y el Museum für Islamische Kunst de Berlín. Dos de las planchas presentan la singularidad de combinar mocárabes con ataurique y una serie de cabezas humanas en relieve.

Palabras clave: Yeserías; Toledo; siglo XV; Victoria \& Albert Museum; Museum für Islamische Kunst de Berlín.
\end{abstract}

\section{THREE MUDEJAR PLASTERWORK PLAQUES IN EUROPEAN MUSEUMS}

These unpublished plaques with a Toledan provenance are in the Victoria \& Albert Museum and the Museum of Islamic Art of Berlin. Two of the plaques are unique in that they combine mocarabe honeycomb arches with ataurique and a series of human heads in relief.

Key words: Plasterwork; $15^{\text {th }}$ century; Toledo; Victoria \& Albert Museum; Museum of Islamic Art of Berlin.

El objetivo de estas notas es dar a conocer tres piezas inéditas de yeserías mudéjares, dos de las cuales debieron formar parte de un mismo friso escultórico en relieve que se dividió para su venta: una se halla en el V\&A (fig. 1) y otra en el Museo de Arte Islámico de Berlín (fig. 2). Sus elementos más característicos son una serie de cabezas que asoman entre mocárabes sobre columnas torsas. La tercera pieza, también en Berlín y decorada con ataurique, formó parte del mismo programa (fig. 3) ${ }^{1}$. El carácter novedoso de este conjunto reside en presentar unos motivos infrecuentes al combinar una estructura arquitectónica con rostros humanos y ataurique.

${ }^{1}$ El estudio de estas piezas fue sugerido por la Dra. Mariam Rosser-Owen, conservadora del Departamento de Arte del Próximo Oriente del V\&A Museum, a quien agradezco las facilidades para ver las piezas en el almacén y que me pusiera en contacto con el Museo de Arte Islámico de Berlín, así como las fotografías de las piezas de este museo. Este trabajo ha sido posible gracias a la concesión de una ayuda del Programa Propio de la Universidad de Córdoba para la realización de una estancia de investigación en Londres. 


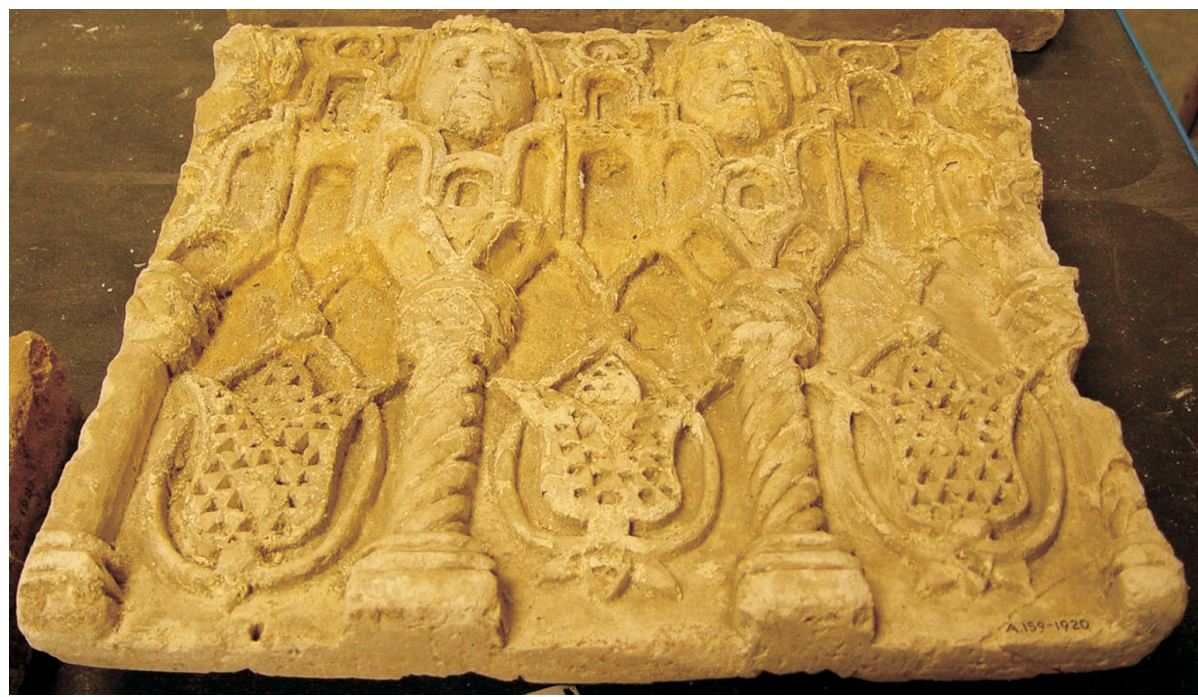

Fig. 1. Placa de yesería mudéjar toledana (registro A.159-1920). Victoria and Albert Museum. Foto: M. ${ }^{a}$ A.J.B.

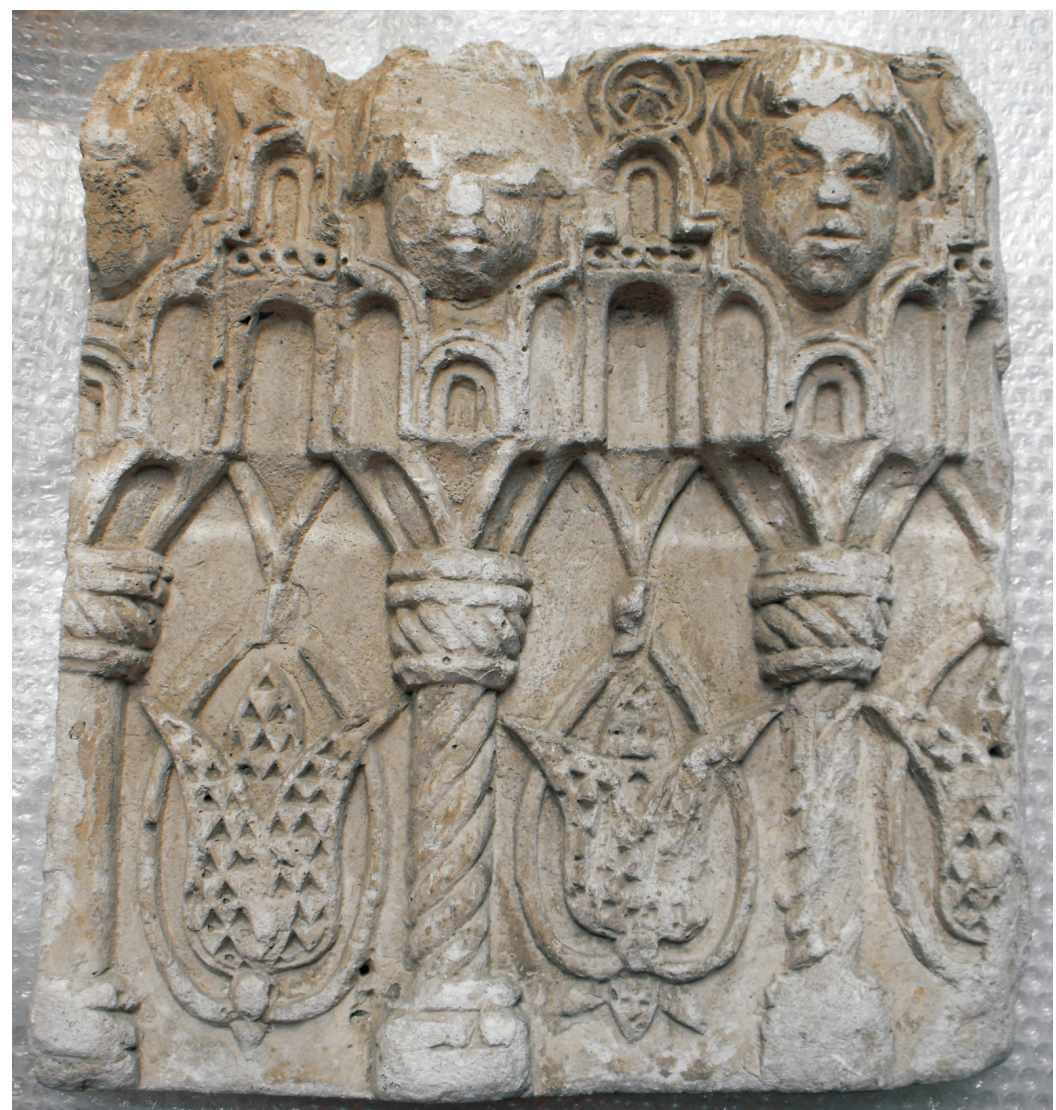

Fig. 2. Placa de yesería mudéjar procedente de Toledo (registro 1.2842). Museum für Islamische Kunst, Staatliche Museen zu Berlin. Foto: M. Rosser-Owen. 


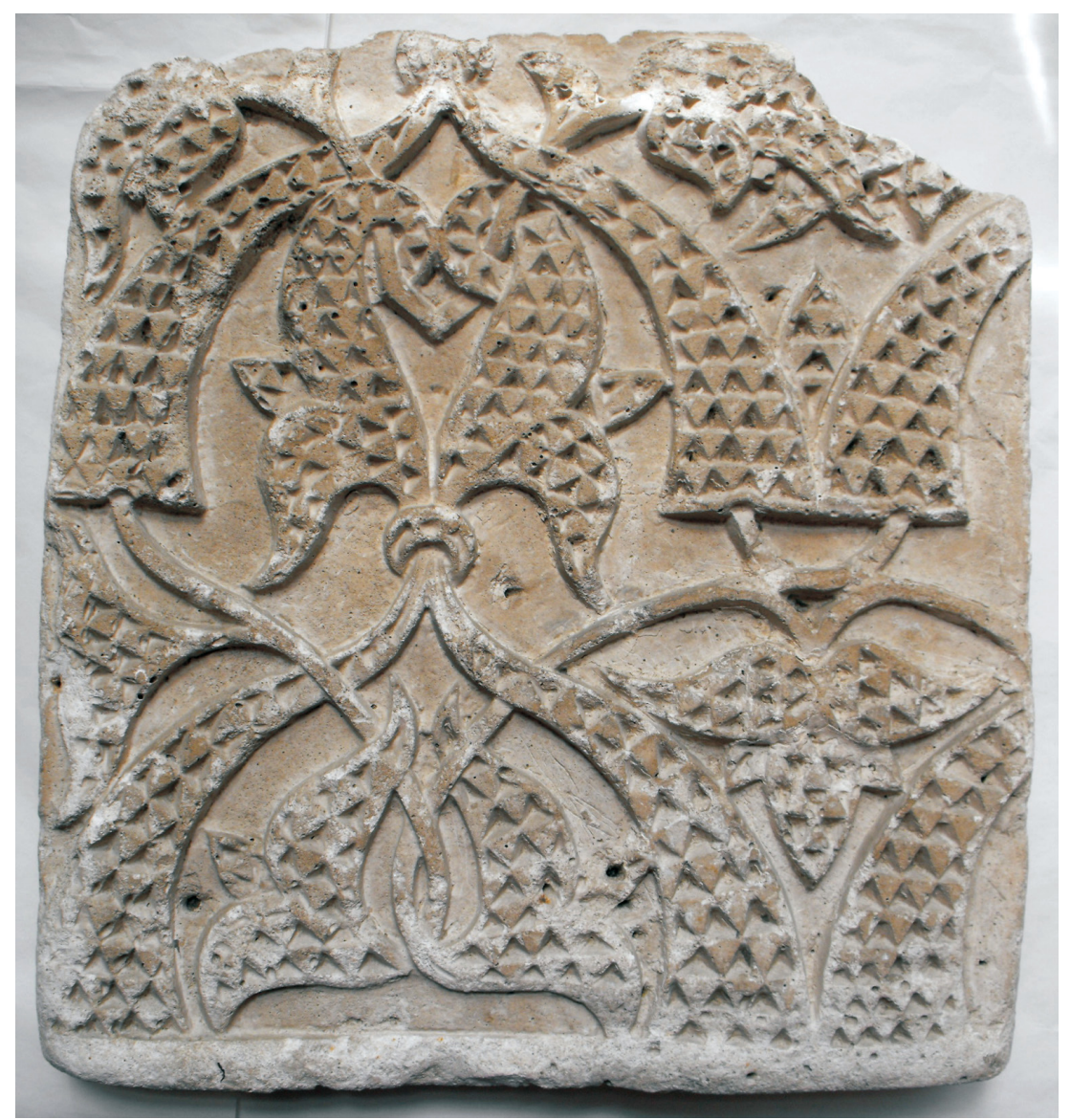

Fig. 3. Plancha de yeso toledana (1.2841). Museum für Islamische Kunst, Staatliche Museen zu Berlin. Foto: M. Rosser-Owen.

\section{Procedencia}

Su procedencia exacta es desconocida; sólo consta que vinieron de Toledo ${ }^{2}$. Una de las piezas (registro A.159-1920) fue adquirida por el Dr. Walter Leo Hildburgh, quien la donó en 1920 al entonces South Kensignton Museum, hoy Victoria and Albert. De familia europea asentada en Nueva York a comienzos del XIX, Hildburgh (1876-1955) es exponente de la atracción que ejerció en la sociedad inglesa el arte español y en especial su capítulo considerado más exótico, el "árabe" y sus consecuencias; y, por otra parte, es reflejo de la intensa política de adquisición de piezas españolas que desplegó el museo en el último tercio del XIX y cuyo adalid fue Juan Facundo Riaño ${ }^{3}$. Movido por el mismo interés, Hildburgh contactó con marchantes y se dedicó a

${ }^{2}$ El inventario de los bienes del cabildo catedralicio, realizado entre 1491 y 1492, arroja información sobre un total de 557 inmuebles. Aunque se describen las habitaciones, no se alude a la decoración (PAssini, 2004: XVI). Por otra parte, el número de edificios históricos destruidos en Toledo, especialmente en el siglo XIX, es muy elevado (MoRENO, 2002) y es posible que de alguno de ellos procedieran las planchas.

3 TRusted, 2006: 225-236. 
comprar piezas o incluso a recogerlas directamente de yacimientos, entre otros de Madinat alZahra; algo que en 1921 llevó a decir a Eric Maclagan, director del Departamento de Arquitectura y Escultura, que "ya ha dejado España bastante limpia de las cosas que más nos interesan", dato recientemente publicado por M. Rosser-Owen ${ }^{4}$ que debe ser una llamada de atención sobre las piezas desconocidas en los depósitos de los museos 5 . Por su parte, las dos piezas del museo alemán ingresaron por medio de Arthur Haseloff (1875-1955) entre 1914 y $1915^{6}$.

\section{Descripción de las piezas. Fuentes, paralelos y derivaciones}

La placa del V\&A (A.159-1920) mide 42,9 cm de altura por 29,8 de anchura. La esquina inferior derecha fue reparada en el Art Work Room? ${ }^{7}$.

En su ubicación original formó parte de un friso decorativo, en el cual también se incluía su pareja de Berlín -registro $1.2482-$, cuya altura de $42,5 \mathrm{~cm}$ viene a coincidir con la del V\&A ${ }^{8}$, aunque no estuvieron contiguas ${ }^{9}$. Ambas planchas muestran arquillos de mocárabes que rematan en nudo de progenie almohade, en el que se inserta lo que pudiera ser una flor octopétala o bien una forma gallonada. Los arcos descansan sobre columnas torsas y otras de fustes lisos. La basa es ática y apoya sobre plinto, mientras que el capitel es sogueado. En los intercolumnios se dispone un motivo muy característico en el arte islámico y su pervivencia, aunque enraizado en la Antigüedad. Se trata de una flor que emerge entre dos hojas, todas ellas grabadas con incisiones denticuladas con el mismo tratamiento que si fueran una piña, aunque no hay que descartar que pudiera tratarse de la propia piña entre dos palmetas, como se ve en la Sinagoga del Tránsito. La particularidad en las planchas es que también estas hojas que flanquean a la central están talladas con el denticulado; motivo inspirado en el arte califal bajo Abd al-Rahman III, como se ve en el arquito del claustro de la catedral de Tarragona (fig. 4), o en el Salón Rico de Madinat al-Zahra. La particular forma en que la flor queda rodeada por un tallo tiene sus precedentes también en lo califal, como sucede en el arranque de la bóveda del antemihrab de la Mezquita de Córdoba bajo al-Hakem II (fig. 5). En las placas dicho tallo se prolonga confundiéndose con las nervaduras que surgen de las columnas para culminar en los arquillos de las muqarnas.

Del arte califal procede, asimismo, la cadeneta o trenzado simple que decora el nicho central de los mocárabes, motivo profusamente empleado en los tallos mediales del acanto de los capiteles del Salón Rico y otros contemporáneos; mientras que el sogueado de los capiteles se remonta a época clásica ${ }^{10}$.

\footnotetext{
${ }^{4}$ Rosser-Owen, 2010: 64.

${ }_{5}^{5}$ Una de las piezas que custodia el V\&A es el Arco de la Botica de la desaparecida Casa del Temple en Toledo, cfr. Jordano (en prensa).

${ }^{6}$ Katalog, 1967: 203-204. Discípulo de Adolf Goldschmidt y Rector de la Universidad de Kiel, fue una de las figuras más importantes del Instituto de Historia del Arte. Coincide la fecha de ingreso de las piezas en el museo con los años en que ejerció de director del Departamento de Historia del Arte del Instituto Histórico de Prusia en Roma. Datos biográficos en NÄGELKE, 1994.

7 Actual Departamento de Conservación del museo.

$8 \mathrm{Su}$ anchura es de $38 \mathrm{~cm}$.

9 Se comprueba observando los extremos laterales que no casan.

${ }^{10}$ En fecha anterior a los ejemplos que aquí se abordan se estaba utilizando, por citar algunos ejemplos, en el intradós del arco de yesería de la sala del Aljibe en Santa Clara de Tordesillas, en la rosca de los arcos mixtilíneos que conforman el friso de la fachada del palacio de Pedro I en el Alcázar de Sevilla, o en la casa toledana del Armiño de la primera mitad del XIV (Martínez Caviró, 1980: 308, fig. 271) y, aunque citemos estos ejemplos mudéjares, ya estaba en el collarino de los capiteles de la mezquita de la Aljafería propiciando la pervivencia de este motivo en el arte andalusí.
} 


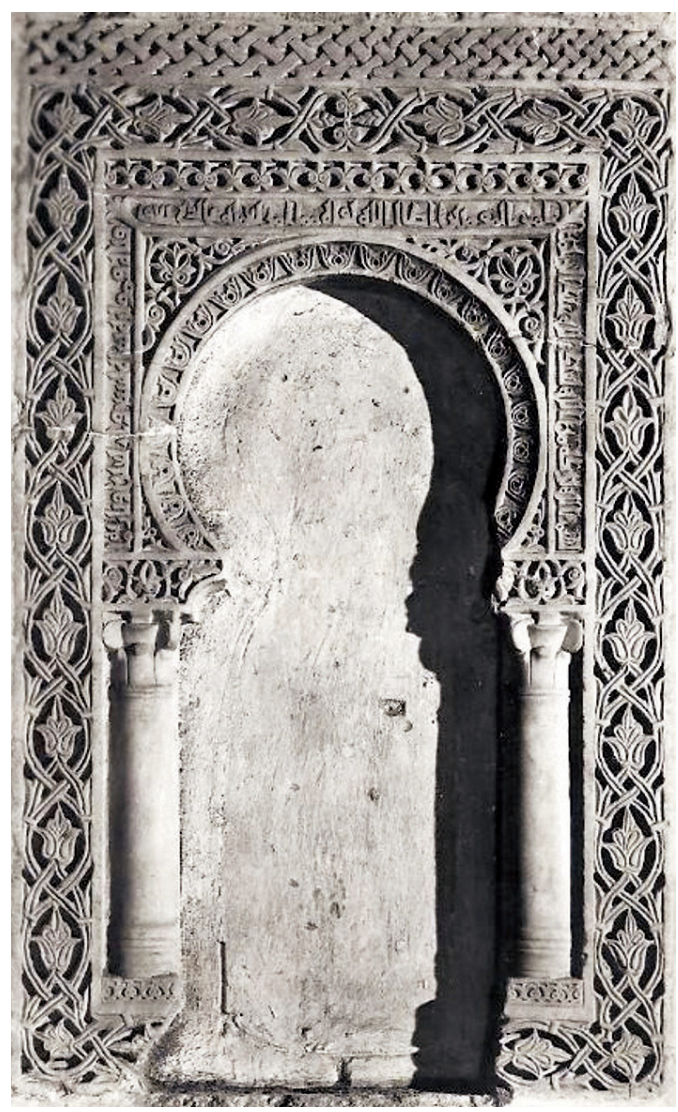

Fig. 4. Arco del claustro de la catedral de Tarragona

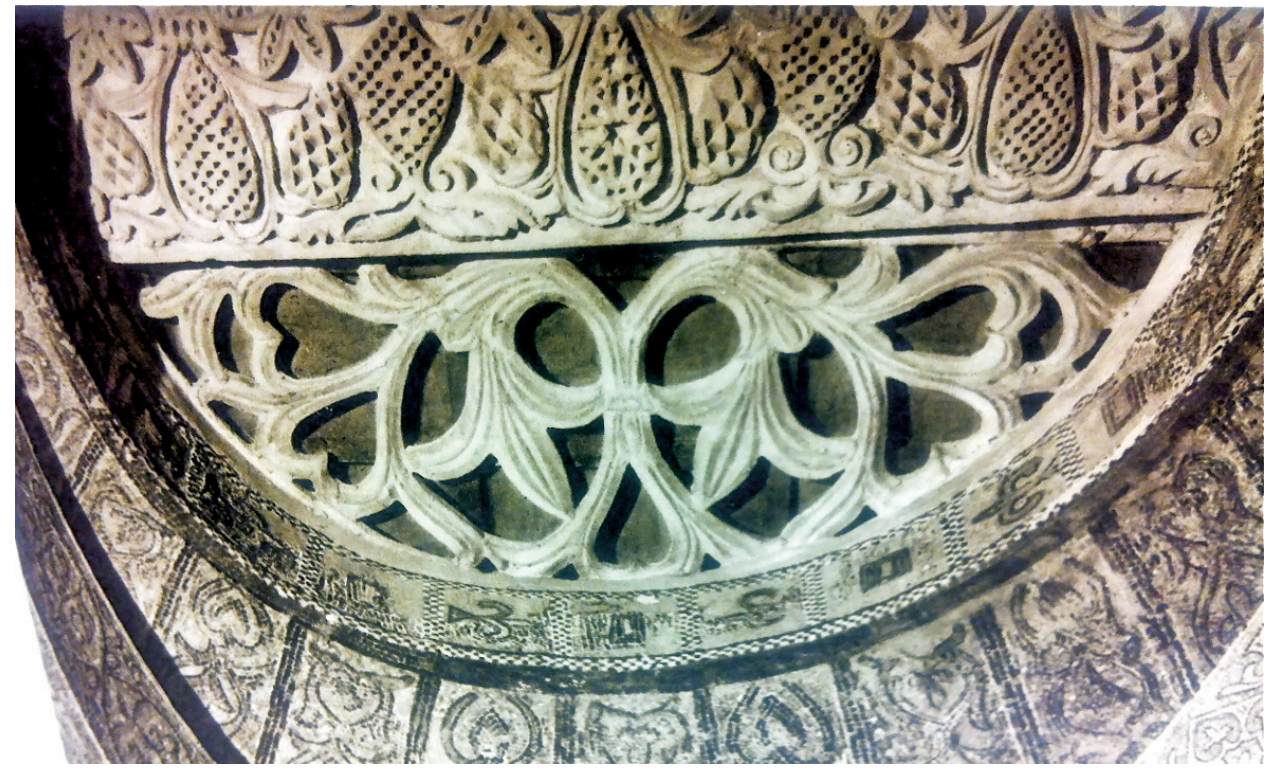

Fig. 5. Arranque de la bóveda del antemihrab. Mezquita de Córdoba. 


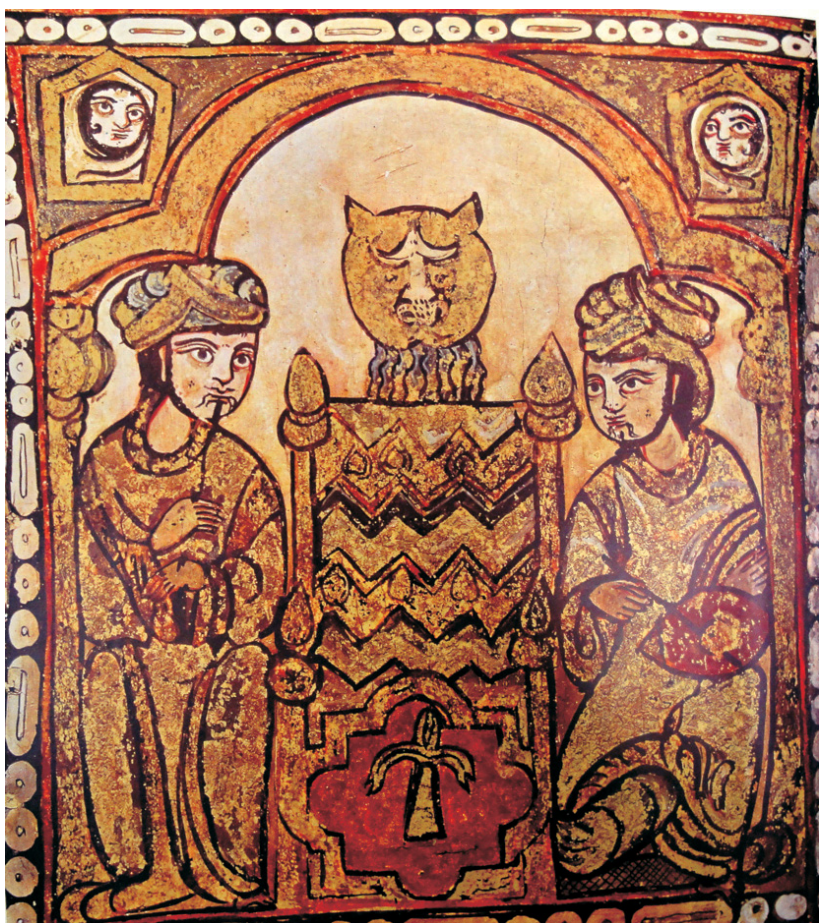

Fig. 6. Dos personajes ante una fuente. Capilla Palatina de Palermo.

Pero el interés de estas placas reside en la introducción de pequeñas cabezas que asoman entre los arcos. El tema no era extraño a otro arte de fusión, el sículo-normando: en una pintura sobre madera de mediados del XII que se halla en el techo de la Capilla Palatina de Palermo se representó un arco en cuyas enjutas figuran dos cabezas de mujeres que contemplan la escena central sobre las "distracciones reales" que tiene lugar en una sala de recepción (fig. 6) ${ }^{11}$.

El uso de motivos figurados tendrá una repercusión limitada en el mudéjar, aunque se erigió en uno de los elementos más vistosos, como demuestra la armadura de la catedral de Teruel (último tercio del XIII). J. Yarza ha intentado explicar su iconografía y establecer paralelismos, entre los que cita la Capilla Palatina de Palermo -aunque son personajes nimbados- o la cubierta de la catedral de Cefalú $(1 / 2 \text { XII })^{12}$.

Este proceso decorativo tuvo su culminación en los espectaculares frisos de arquillos con mocárabes y es-

cenas figuradas (Sala del Solio - ca. 1456- del Alcázar de Segovia y Salón de Linajes -1492- del palacio del Infantado), cerrando el repertorio unas cabezas de gran fuerza expresiva alojadas bajo los mocárabes del arrocabe del palacio de Avellaneda (Peñaranda de Duero). Aunque realizado hacia 1530, no cabe duda de que la semilla de esta fórmula había arraigado, incluso en técnicas y soportes variopintos. En muebles destaca el tríptico relicario del monasterio de Piedra (1390), hoy en la Real Academia de la Historia; en yeso está el caballero en un arco del convento de San Juan de la Penitencia (Toledo) ${ }^{13}$; e incluso se aplicó en elementos como la reja de la capilla mayor del coro largo de Santa Clara de Tordesillas, cuya viga luce mocárabes que albergan ángeles portando los instrumentos de la Pasión (fig. 7). Por su parte, la armadura del presbiterio descansa sobre un arrocabe cuajado de muqarnas que acogen a los santos.

Aunque la utilización de un friso de arquillos con elementos decorativos ocupando los espacios libres es fórmula ancestral y recurrente, para el mudéjar hemos de mirar hacia Córdoba, fuente constante de inspiración a lo largo de centurias, como pone de manifiesto el tablero de mármol procedente del antiguo alcázar emiral y califal de esta ciudad (fig. 8), donde la piña entre dos hojas está tanto en los intercolumnios como en las enjutas y significativamente unida al hom. Más cercano en el tiempo en cuanto a la disposición de elementos figurados entre los mocárabes está el arte nazarí, donde se emplearon veneras, como sucede tempranamente en el

\footnotetext{
11 Ettinghausen, 1962: 48.

12 YARZA, 1991: 300-301.

13 Lo reproduce J. Amador de los Ríos en Monumentos arquitectónicos de España, 385-386.
} 


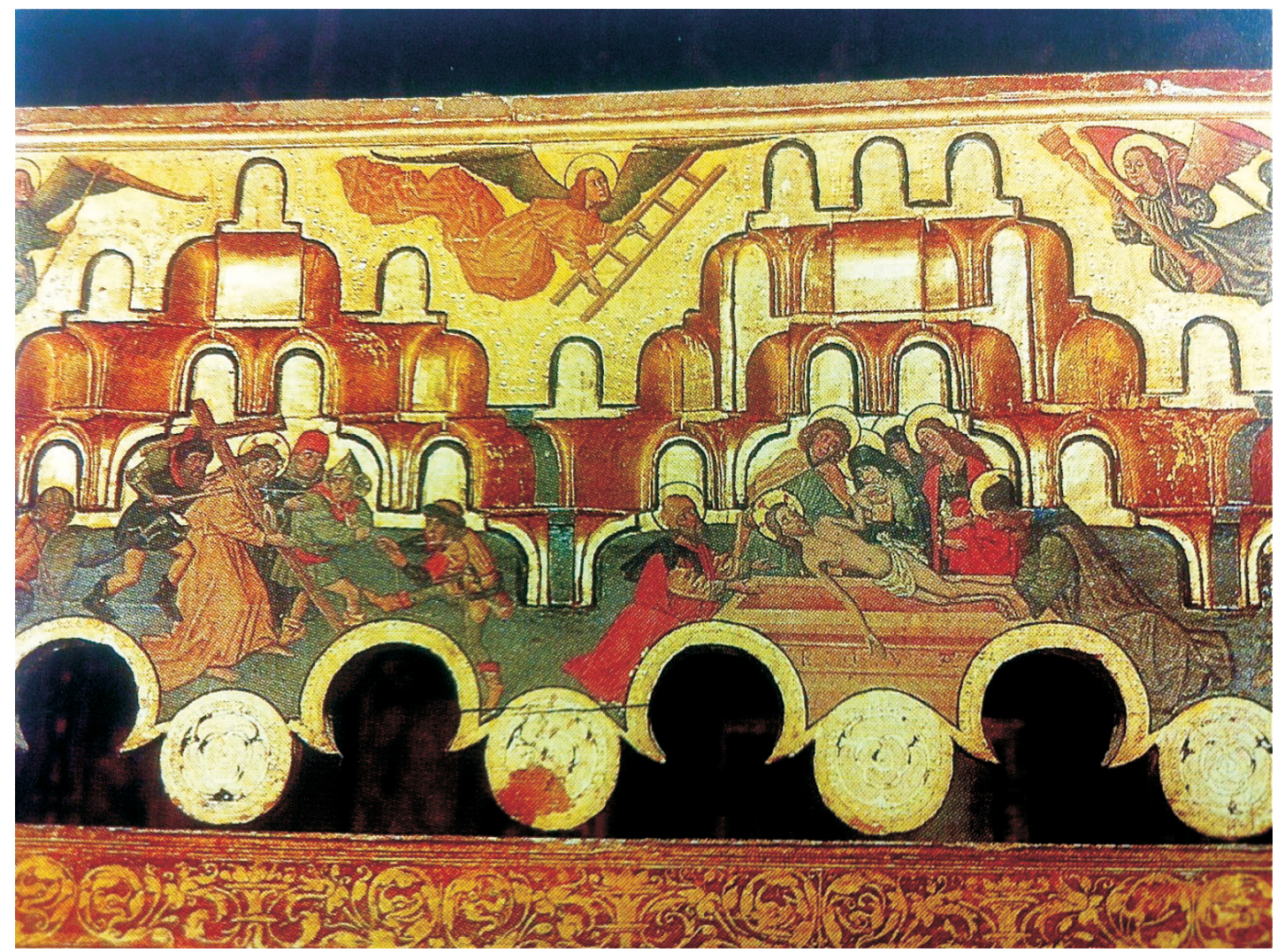

Fig. 7. Detalle de la viga. Reja de la capilla mayor del coro largo. Convento de Santa Clara de Tordesillas.

Fig. 8. Tablero de mármol procedente del antiguo alcázar

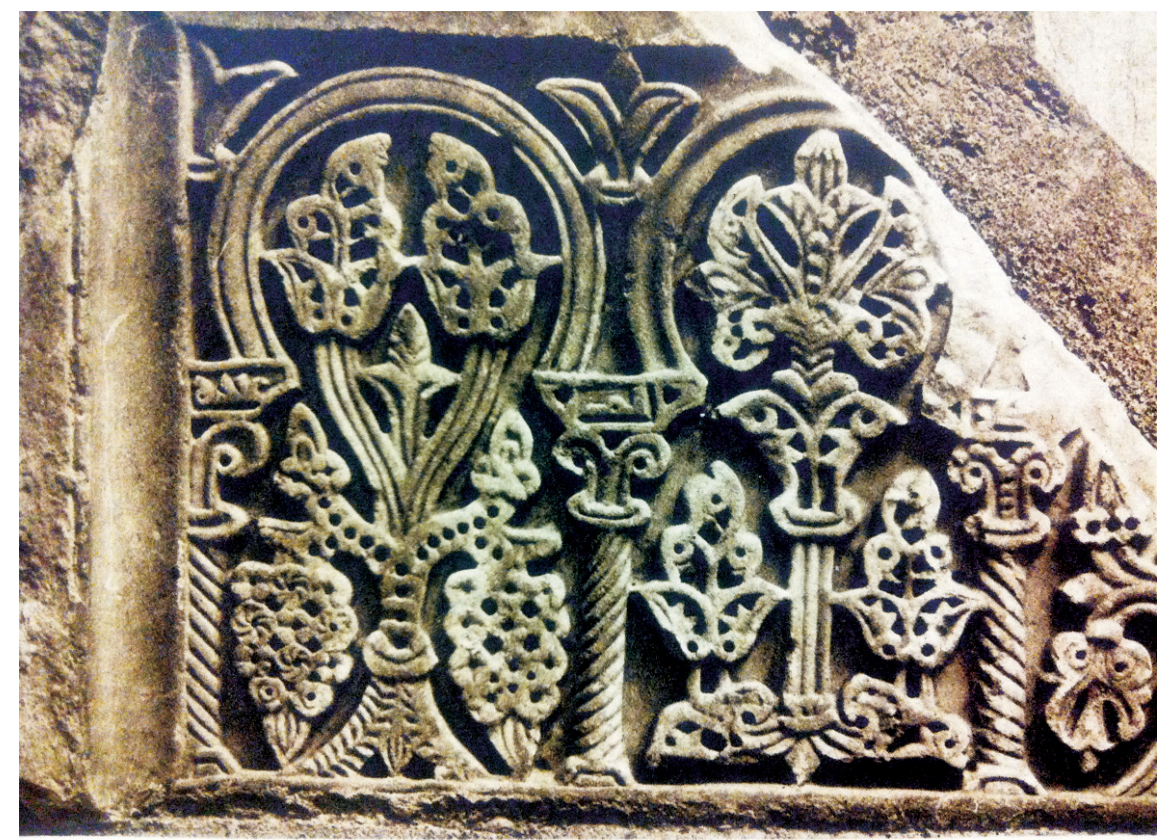

Arch. esp. arte, LXXXv, 340, octuBre-DICIEMBRE 2012, 351-387, ISSN: 0004-0428 
Partal. En el mudéjar castellano, por el peso que cobra la tradición cristiana, se produce la transmutación en figuras antropomorfas o escenas figuradas ${ }^{14}$.

La fuente de inspiración en relación a la inserción de cabezas humanas pudo ser la escultura gótica monumental francesa, donde aparecen en triforios (Nevers) ${ }^{15} \mathrm{o}$ en claves de bóvedas (Noyon) (fig. 9) ${ }^{16}$. Su apariencia nos remite a las placas toledanas (fig. 10) y gozaron de su mayor éxito en portadas ${ }^{17}$ y sepulcros ${ }^{18}$. En el mudéjar es digno de mención el sepulcro en yeso del infante Fernán Pérez en la capilla de Belén del convento de Santa Fe (Toledo), fechado en torno

Fig. 9. Clave de bóveda. Catedral de Noyon.
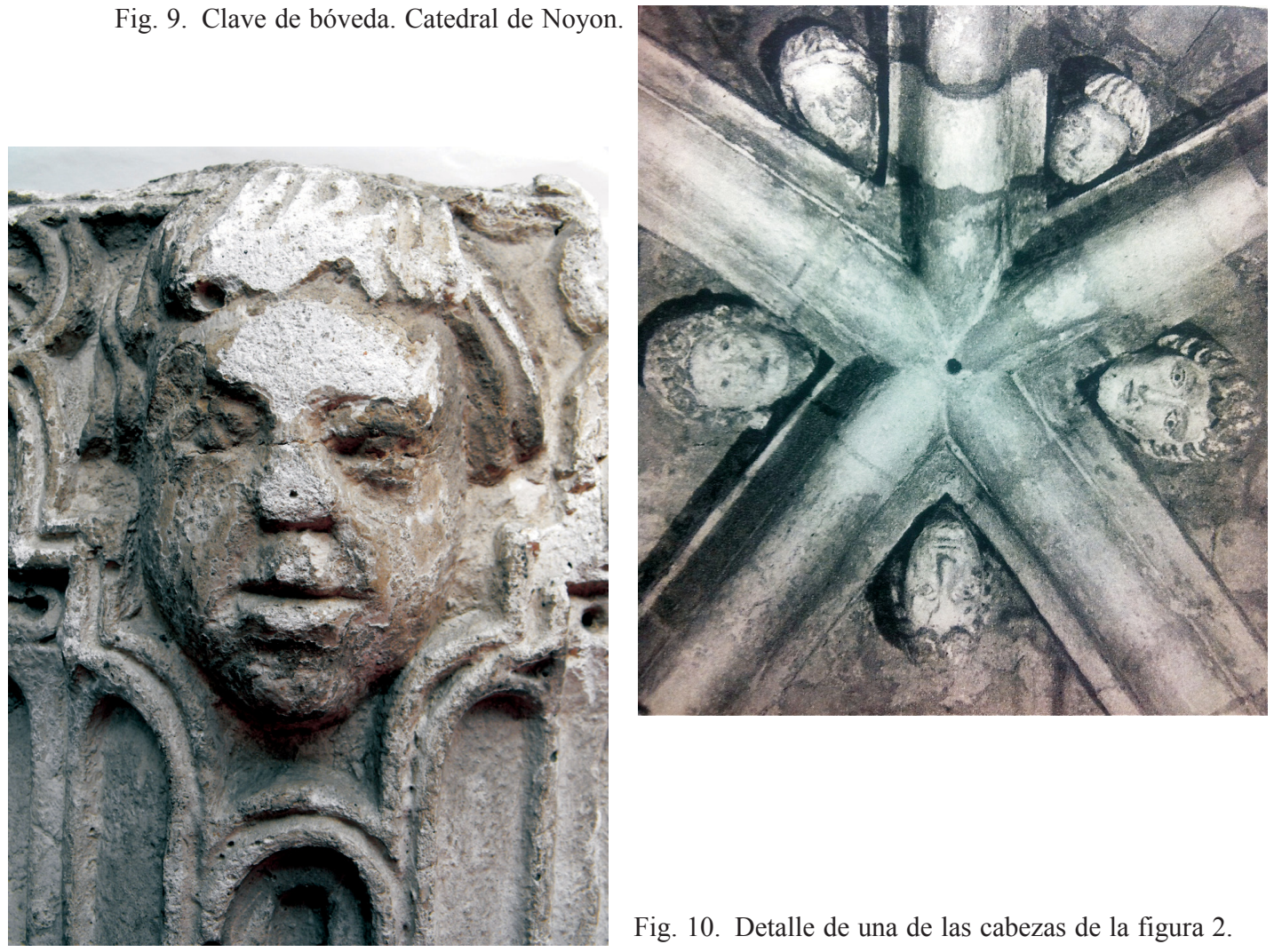

Fig. 10. Detalle de una de las cabezas de la figura 2.

${ }^{14}$ Que esta fórmula y sus derivaciones debieron tener éxito lo manifiestan en fechas más tardías los capiteles de mocárabes con cabezas en los ángulos del claustro de Santa Clara de Palma del Río en Córdoba (primera mitad del XVI), o las cabecitas labradas en los pilares del patio del palacio de Fuensalida en Toledo (ca. 1. a 1 1 XV).

15 Ver dibujo 17 en Viollet le Duc [en línea]: http://fr.wikisource.org/wiki/Dictionnaire_raisonné_de_l'architecture_ française du XIe au XVIe siècle - Tome 9, Triforium (consulta: 8/02/12).

16 Ángeles de cuerpo entero en dibujo $\overline{3}$ de Viollet le Duc [en línea]: http://fr.wikisource.org/wiki/Dictionnaire_raisonné_de_l'architecture_française_du_XIe_au_XVIe_siècle_-_Tome_3,_Clef (consulta: 8/02/12)

${ }_{17}$ Los ejemplos en la escultura monumental francesa son abundantes; por citar algunos: los ángeles asomando por el extradós del arco en el pórtico central de la fachada occidental de Notre Dame de París, o los ángeles que aparecen con coronas por encima del extradós del arco que cobija a la figura de Cristo en el Juicio Final de la fachada oeste de la catedral de Bourges.

${ }^{18}$ En algunos se produjo la antropomorfización de las corlas, como sucede en el sepulcro del obispo Domingo de Arroyuelo fallecido en 1385, de la catedral de Burgos. Cabezas aplicadas directamente sobre el túmulo del sepulcro se hallan en el del arzobispo don Pedro Tenorio (1399) en la capilla de San Blas de la catedral de Toledo. Entre los medallones tetralobulados con escotaduras de su sepulcro también se insertaron unas cabecitas. En la misma línea está el de doña María Meléndez de Orozco, la "Malograda", fallecida en 1399. 
a 1242, donde el alfiz aparece cuajado de mocárabes disponiéndose en las albanegas sendos ángeles ${ }^{19}$. Es interesante comprobar la asociación de mocárabes con ángeles, como sucede en el caso de los turiferarios de la capilla del Corpus Christi (ca. 1260) de la catedral toledana ${ }^{20}$.

Mayor semejanza en cuanto a la colocación de cabezas entre los arcos se observa en el triforio de la girola y brazo oriental del crucero de la catedral de Toledo llevado a cabo por el maestro Petrus Petri en la segunda mitad del XIII, que presenta además la particularidad, como es sabido, de que los arquillos son lobulados de progenie hispanomusulmana, por lo cual pudo ser una de las fuentes más cercanas y directas en que se inspiró el autor de las planchas ${ }^{21}$.

La plancha 1.2841 del museo de Berlín fue realizada para el mismo lugar que las anteriores (fig. 3) 22 $^{2}$ aunque el tema principal lo constituyen las palmetas disimétricas afrontadas, anudadas en su tallo o peciolo, y hojas de pimiento, todas ellas rellenas de triangulillos con la misma técnica que las flores que aparecen en las placas con cabecitas. Se da la particularidad de que la palmeta asimétrica se complementa con una piña en el eje que separa las dos hojas; modalidad ampliamente extendida en Toledo, como se ve en algunas enjutas de los arcos decorativos del Tránsito $^{23}$. Los paralelismos más cercanos están en una plancha de una de las puertas del palacio de Peñaranda de Duero ${ }^{24}$ y en unas yeserías del patio del hospital de Santa Cruz de Toledo ${ }^{25}$.

\section{Técnica}

En el reverso de la pieza 1.2482 se observa una serie de incisiones de varios milímetros de profundidad formando una retícula en negativo que aparece también en placas nazaríes ${ }^{26}$. Su finalidad era la de contribuir a la fijación sobre el soporte de yeso, ya que permitía que éste se adentrara proporcionando una superficie irregular.

En la pieza decorada con hojas se observa la cabeza de un clavo de hierro forjado. Estos clavos se solían colocar antes de que el yeso fraguara en el molde hincando la cabeza dentro, de manera que una vez que el material se endurecía, el clavo quedaba en el interior asomando la cabeza y quedando prácticamente enrasado con la superficie del yeso; de esta manera se reforzaba la pieza. A pesar de que la lógica oxidación de los clavos podía ocasionar problemas, sin embargo, fueron utilizados asiduamente en las yeserías ${ }^{27}$.

\section{Cronología}

La ficha catalográfica del V\&A sitúa su placa en el siglo XV, mientras que el Islamische Kunst da una cronología más amplia para las suyas, entre el XIV y el XV. Según adelantábamos

\footnotetext{
19 INVENTARIO, I, 1983: 136-137.

20 InVENTARIO, I, 1983: 262.

21 En la catedral de Burgos también se dispusieron cabezas de rasgos individualizados en el extradós de los grandes arcos que forman el triforio, obra del XIV.

22 Medidas: $35 \times 32 \mathrm{~cm}$.

23 Dibujo en Pavón, 1988: 185.

24 Foto en PAVÓN, 1988: CLVI.

25 Archivo fotográfico CSIC, reg. 80371, serie C, 1934.

${ }^{26}$ Como se ha descubierto en una pilastra del Patio del Harén de la Alhambra recientemente.

27 Un ejemplo es la Sala de los Reyes en la Alhambra, donde las adarajas se fijaron gracias a múltiples clavos que se pueden ver en el trasdós de la cúpula de mocárabes (RUBIO, 2010: 204-207). También están sujetando la decoración paramental y los rizos de la bóveda de la Capilla Real en la Mezquita-Catedral de Córdoba.
} 
al inicio, la singularidad de los elementos de estas piezas y la falta de paralelos claros dificulta el intento de precisar esta datación, teniendo en cuenta la multiplicidad de motivos en el mudéjar y su dilatada pervivencia. A falta de datos documentales y basándonos en el análisis estilístico y en paralelismos se podría situar la realización de estas planchas en torno a la primera mitad del XV. Para ello se ha tenido en cuenta el estilo del ataurique, cuyos paralelos más próximos son los de Peñaranda de Duero y la Santa Cruz, tanto por el tipo de palmetas como por el nudo que forma el tallo bajo el peciolo, también presente en una ventana del patio de los Aljibes de la Concepción Francisca de comienzos del XVI. Por otra parte, las cabezas en medio relieve podrían suponer un avance en el mudéjar al superar la fase de figuras planas en las yeserías, cuyo punto álgido se produce en la segunda mitad del XIV (Alcázar de Sevilla, palacio de Tordesillas, de Suero Téllez, casa de San Justo -estos dos últimos en Toledo-, etc.), y supone una mayor apertura a la escultura monumental gótica, como también revela el peinado, característico de la moda francesa de finales del XIV.

\section{Hacia una interpretación iconográfica}

Fue T. Pérez Higuera quien interpretó la decoración figurativa de las yeserías del palacio de Suero Téllez como una representación del jardín del paraíso ${ }^{28}$. En nuestra opinión los rostros que analizamos podrían encuadrarse en el mismo contexto. Recordemos la disposición de las piñas bajo los mocárabes que, envueltas por un tallo, quedan conectadas con las figuras antropomorfas de la parte superior. En esta línea argumental se podría plantear si algún texto como el Libro de la escala de Mahoma pudo influir con alguna de sus descripciones del ascenso a los cielos del profeta y su visión de los siete estadios del paraíso, donde se alude a los ángeles que aguardan a aquellos que han cumplido con los preceptos del islam. Realmente, su colocación entre los mocárabes, como si se tratara de la simulación de una arquitectura, recuerda los suntuosos pabellones del jardín, así como también las representaciones góticas de la Jerusalén celestial. Las similitudes entre la religión cristiana e islámica, estudiadas por Asín Palacios, facilitaron la simbiosis cultural que se produjo en el mudéjar.

La nula diferenciación de los rasgos fisiognómicos de estos personajes en las placas, así como sus rostros de apariencia infantil contribuyen a su identificación con ángeles o querubines. Su asociación a la Jerusalén celestial en el románico y el gótico dio lugar a innumerables ejemplos en los que por encima del friso de arcos o aprovechando las enjutas se disponían unas torres o edificios que simulaban ser el paraíso.

Volviendo al Libro de la escala de Mahoma que Alfonso X el Sabio mandó traducir en 1260, su influencia se hizo notar en textos cristianos a partir del XIII hasta el XV, contribuyendo a la expansión de la escatología musulmana. Cuando Mahoma penetró a través de las puertas del primer cielo "que eran maravillosamente hermosas", vio una multitud de ángeles "que las protegían" 29 , que estaban ordenados, en hileras, juntos ${ }^{30}$, y "todos mantenían sus ojos fijos en Dios y no hacían otra cosa que cantar y alabar a Dios con toda devoción"31.

La jerarquía celestial islámica incluye, como la cristiana, a los querubines. Los hadices relatan que están situados cerca de Dios y siempre alabándole ${ }^{32}$. Mahoma indica que "todos tenían sus cabezas erguidas y con sus ojos miraban tan directamente en línea recta que ni elevaban la

\footnotetext{
28 PÉREZ, 1988: 37-52.

29 Libro, 1996: 59.

30 Una muestra en la visita al tercer cielo (Libro, 1996: 62).

31 Libro, 1996: 67.

32 Libro, 1996: 75.
} 
vista ni la bajaban, por el temor que tenían a Dios"33; imagen que nos recuerda los rostros que aparecen en las placas.

Aunque con los datos que tenemos es imposible saber dónde y para qué contexto se hicieron estas placas, lo cierto es que esta hipótesis de una representación del paraíso se afianza cuando en numerosas "qubbas" se coloca, por encima de los paramentos con decoración vegetal, un friso de arquillos o mocárabes, que podría asociarse a la idea del pabellón. En el retablo bordado del obispo Pedro de Montoya, obra del tercer cuarto del s. $\mathrm{XV}^{34}$ unos ángeles se asoman entre los arquillos mientras otros contemplan la escena principal desde los medallones en los que se hallan insertas sus cabezas.

En la Escala de Mahoma también se relata cómo la multitud de ángeles que rodean a Dios repitiendo "Le hille halalla" (No hay otro dios sino Dios), "están ordenados por filas tan estrechamente que asemejan el muro de una ciudad o de un castillo, construido con hileras (de piedra)"35. La cuestión es si los arquillos que origina la sucesión de mocárabes no serían una transposición de esta imagen del castillo o muralla, que equivaldría a la Jerusalén celeste en el mundo cristiano.

Un testimonio más a favor de esta posible interpretación es el conjunto de ángeles pintados en la armadura del castillo de los Luna en Mesones de Isuela (Zaragoza) en combinación con lacería, cuya lectura es la de una representación de la bóveda celeste en la cual los ángeles iluminan con las antorchas el paso del alma del difunto a la Jerusalén celestial ${ }^{36}$.

A esta interpretación de los ángeles que observan y al mismo tiempo acompañan al fiel podría sumarse una magnífica ilustración que representa a Jibril -el arcángel Gabriel- mientras lleva sobre sus hombros a Mahoma más allá de las montañas ${ }^{37}$, donde algunos ángeles figuran apostados detrás de las rocas asomando sólo sus cabezas o parte del torso ${ }^{38}$.

Tampoco hay que descartar que se tratara de niños en lugar de ángeles, puesto que los textos tradicionales hablan de la presencia de unos niños "tan bellos que nadie podría describirlos, que andan entretenidos por sus parajes, conocen a los que entran, les llaman por su nombre, les dan la bienvenida y anuncian las cosas de que podrán disfrutar"39, además de acompañarles hasta los jardines del paraíso ${ }^{40}$. En el contexto cristiano numerosas cabecitas infantiles pueblan la escultura monumental, según avanzábamos, a veces identificadas claramente con ángeles, pero otras no. La Puerta del Perdón de la catedral de Toledo es una muestra.

Existen ejemplos en los que la identificación con meros observadores de acontecimientos o curiosos son evidentes, como el sepulcro del infante Felipe en Villalcázar de Sirga (Palencia) del último tercio del XIII, pero en nuestra opinión no parece que fuera este el caso de las planchas

33 Libro, 1996: 81.

34 Ver imagen en Chicago Art Institute: http://www.artic.edu/aic/collections/artwork/41449?search_id=3 [Consultado: 31/01/2012].

35 Libro, 1996: 77.

36 Álvaro, 2003: 82, fig. 60.

37 Véase la ilustración en Grabar, 2009: 48, fig. 43. La página ilustrada procede del Mirajnama o "Libro de la Ascensión del Profeta", Álbum Sarai. Fechado a comienzos del siglo XIV en Tabriz (Irán), se encuentra en Estambul, Topkapi Sarayi Müzesi hazine 2154, fol. 42b.

${ }^{38}$ De la aceptación que tuvo el tema de los ángeles en el arte islámico es buena prueba la exquisita imagen de la protección celestial que ilustra la portada de un "Quinteto" o colección Khamsa por Khwaju Kirmani (1437-38) (Washington, the Freer Gallery and Arthur Sackler Gallery, Smithsonian Institution, imagen en: http://www.asia.si.edu/collections/singleObject.cfm?ObjectNumber=S1986.34 (consultado: 3/02/2012). Sobre su interpretación véase Grabar, 2009: 57.

${ }^{39}$ Libro de la Escala..., p. 72.

${ }^{40}$ Libro de la Escala..., p. 97. 
toledanas por la razón, entre otras ya mencionadas, de que sus protagonistas están aislados y, en todo caso, relacionados con la tercera placa cubierta de vegetación.

Estos ejemplos y otros que se mencionan en estas páginas evidencian que la representación de cabezas fue un tema de especial significación que compartieron cristianos y musulmanes.

\section{BIBLIOGRAFÍA}

Álvaro Zamora, M. ${ }^{a}$ I. Borrás Gualis, G. M. Sarasa Sánchez, E. Los Mudéjares en Aragón, Zaragoza, Caja de Ahorros de la Inmaculada de Aragón, 2003.

Álvaro Zamora, M. ${ }^{a}$ Isabel. "La decoración, como elemento formal primordial en el arte mudéjar" en Borrás Gualis, Gonzalo M. (dir.), Mudéjar. El legado andalusí en la cultura española, Zaragoza, Universidad de Zaragoza, 2010, pp. 275-291.

Katalog. Museum für Islamische Kunst, ficha catalográfica 365-366, 1967, pp. 203-204.

Ettinghausen, R. La peinture arabe, Geneve, Skira, 1962.

Grabar, O. Masterpieces of Islamic Art. The decorated page from the 8th to the $17^{\text {th }}$ century, Munich, Prestel, 2009.

Inventario artístico de Toledo, I, Revuelta Tubino, Matilde (coord.), Madrid, Ministerio de Cultura, 1983.

Jordano Barbudo, M. Á. "El arco mudéjar de la botica de los Templarios en el Victoria \& Albert Museum de Londres", Actas del XII Simposio Internacional de Mudejarismo, Teruel, 2011 (en prensa).

Libro de la escala de Mahoma: según la versión latina del siglo XIII de Buenaventura de Siena. Viguera Molins, M. . J. (pr.); Oliver Domingo, J. L. (tr.), Madrid, Siruela, 1996.

Moreno Domínguez, Luis. Alguacil San Félix, Francisco J. Alguacil San Félix, P. El Toledo invisible, Toledo, Colegio Oficial de Arquitectos, 2002.

Nägelke, Hans-Dieter. Kunstgeschichte in Kiel. 100 Jahre Kunsthistorisches Institut der Christian Albrechts Universität, 1893-1993, Universidad de Kiel, 1994.

Passini, Jean. Casas y casas principales urbanas. El espacio doméstico de Toledo a fines de la Edad Media, Toledo, Universidad de Castilla-La Mancha, 2004.

Pavón Maldonado, Basilio. El arte hispanomusulmán en su decoración geométrica, Madrid, Instituto de Cooperación con el Mundo Árabe, 1976.

Pavón Maldonado, Basilio. Arte toledano. Islámico y mudéjar, Madrid, Instituto Hispano-Árabe de Cultura, 2. ${ }^{\mathrm{a}}$ ed, 1988.

Pérez Higuera, M. ${ }^{a}$ Teresa. "El Jardín del Paraíso. Paralelismos iconológicos en el Arte Hispano Musulmán y Cristiano Medieval". AEA, 61, 241, 1988, pp. 37-52.

Rosser-Owen, Mariam. "Coleccionar la Alhambra: Owen Jones y la España Islámica en el South Kensignton Museum" en Calatrava, Juan (ed.), Owen Jones y la Alhambra, Granada, Patronato de la Alhambra y Generalife, 2011, pp. 43-69.

Rubio Domene, R. Yeserías de la Alhambra. Historia, técnica y conservación, Granada, Junta de Andalucía, Universidad de Granada, 2010.

Trusted, M. "In all cases of difference adopt Signor Riaño's view", Journal of the History of Collections, 18, 2, 2006, pp. 225-236.

Yarza Luaces, Joaquín. "Santa María de Mediavilla, Teruel: pintura de la techumbre mudéjar" en Borrás Gualis, Gonzalo M. (coord.), Teruel mudéjar. Patrimonio de la Humanidad, Zaragoza, Ibercaja, 1991, pp. 239-318. 